\title{
PEMETAAN MEDAN GEOPATIS SEBAGAI SALAH SATU KONSTRAIN PADA PERENCANAAN ZONING DAN BLOCKING INTERIOR RUMAH TINGGAL Studi Kasus: Lahan di Jalan Budi Indah no.9
}

\author{
Stella Sondang \\ Universitas Kristen Maranatha \\ stellasondang@gmail.com
}

\begin{abstract}
Abstrak : Manusia yang berada dan merupakan bagian dari alam semesta ini sejak ribuan tahun yang lalu telah mengembangkan sarana untuk merasakan atau mendeteksi adanya energi yang memancar dari bawah tanah atau yang disebut aliran medan geopatis. Energi ini ada yang bersifat positif dan ada yang bersifat negatif. Energi negatif yang dihasilkan oleh aliran medan geopatis dapat menyebabkan manusia menjadi sakit jika manusia berada diatas aliran tersebut sehingga perlu dihindari agar manusia yang berada di atas permukaan tanah dapat beraktivitas dengan maksimal dan sehat.

Rumah merupakan tempat manusia berlindung, bertumbuh dan berkembang. Hampir sepertiga kehidupan manusia dihabiskan di dalam rumah dan setiap harinya manusia beristirahat sekitar 6 sampai 8 jam (tidur) untuk mendapatkan energinya kembali agar dapat beraktivitas dengan baik dan sehat secara jasmani dan mental. Penelitian ini mencoba untuk memetakan aliran negatif medan geopatis yang ada pada suatu lahan hunian dengan menggunakan alat khusus dengan tujuan menghindari pola aliran medan geopatis sehingga seorang perencana desain hunian dapat merencanakan zoning dan blocking yang tepat agar manusia yang tinggal di dalamnya dapat terhindar dari aliran negatif tersebut. Penelitian ini juga membuktikan bahwa pemetaan medan geopatis dapat mendukung penentuan denah perancangan, terutama dalam perancangan rumah tinggal.
\end{abstract}

Kata Kunci : Pemetaan Medan Geopatis, Zoning, Blocking

\begin{abstract}
Humans are part of this universe thousands of years ago has developed a sense to detect the presence of_egati from the earth itself or the so-called flow field geopatis. This_egati can be separated into positive and negative energy. Negative energy generated by the flow field can lead to human become ill if man is above the flow for a long times. To avoid that, humans above the soil surface must move up to other place for become healthy.

People build homes for they shelter, grow and develop. Nearly a third of human life is spent in the home and about 6 to 8 hours a day humans do rest to get the energy back to move well and healthy physically and mentality. This study tries to map the flow of negative terrain geopatis that exist in a land occupancy by using a special tool in order to avoid the flow pattern field geopatis. So that a planner residential design can plan zoning and blocking the right so that people who live in it can avoid the flow_egative. Also proff that maping the flow of_egative terrain geopatis can support space planning especialy for residential plan.
\end{abstract}

Keywords : Geopathic Field Mapping, Zoning, Blocking

\section{PENDAHULUAN}

Bola bumi memiliki medan magnetis yang terpancar secara teratur dan sudah lama dikenal, diselidiki serta diukur. Namun ada tempat-tempat tertentu yang gelombang atau gaya magnetisnya berlainan. Daerah-daerah tersebut disebut medan geopatis yang $80 \%$ disebebkan oleh kisi bumi, aliran cair dalam tanah (umumnya air yang mengalir), retakan geologis dan mineralologis serta timbunan mineral tertentu dan jenis lain yang belum ditetapkan. Kisi bumi merupakan jaringan sistematis yang terbagi diatas bola bumi yang salah satunya dikenal dengan sebutan Kisi Hartman yang dapat diamati dari laut yang berbentuk arus dan ombak 
yang lurus. Garis yang lebih kuat dapat menyebabkan apa yang disebut oleh pelaut sebagai "laut mati".

Di daratan, tanah tersusun dari berbagai macam mineral yang dapat ditembus oleh air dana da yang tidak. Ini menyebabkan air dari permukaan tanah, misalnya air hujan merembes ke tanah sampai ke lapisan yang menahannya. Lalu dalam lapisan yang dapat ditembus dan terletak di atas lapisan keras air mengalir ke tempat yang lebih rendah. Air tersebut bersifat bipolar yang memiliki kutub positif dan negatif yang mengandung bermacam-macam mineral dalam bentuk ion dan ada juga yang bermuatan listrik. Pada saat mengalir, molekul-molekul air yang dikelilingi anion dan kation berputar seperti dynamo yang menghasilkan gaya elektromagnetis yang arahnya menembus lurus keatas, inilah yang disebut aliran medan geopatis. Secara harafiah gaia berarti bumi, dan pathos artinya menderita atau sakit. Jadi medan geopatis adalah medan yang mengganggu kesehatan manusia dan juga mahluk hidup lain bahkan benda-benda elektromagnetik yang erada di atasnya.

Manusia yang berada dan merupakan bagian dari alam ini sejak ribuan tahun lalu telah mengembangan sarana untuk merasakan atau mendeteksi adanya energi ini sehingga dapat mengambil keuntungan dari energi positif dan menghindari energi yang merugikan. Kemampuan merasakan dan mendeteksi sebenarnya dimiliki oleh semua mahluk hidup. Pada tahun 1930 seorang pendeta bernama Abbe Bouly didusun Haderlot, Pas de Calais Perancis Utara menggunakan istilah Radiesthesia yang merupakan kombinasi dari kata lain yaitu Radius (radiasi) dan kata Yunani aistheis (kepekaan), oleh Karen aitu radiesthesia adalah pendeteksian atau pencarian radiasi yang dipancarkan oelh alam semsta diantaranya mineral/ logam, tumbuhan, hewan dan manusia. Kemmapuan ini juga sebenarnya telah dikembangkan oleh bangsa Cina kurang lebih 4000 tahun yang lalu atau 2000 tahun sebelum masehi dimana pada masa itu digunakan untuk mencari sumber air dibawah tanah.

Kemapuan tersebut dalam Bahasa Inggris disebut Dawsing yang artinya menurut kamus Oxford Advanced Learner's Dictionary of Current English adalah "searching for underground water or metals by using a Y shaped stick or rod". Dowsing semakin dikenal terutama di negara negara Inggris, Belada, Amerika, jerman dan India terbukti dengan adanya asosiasi Dowser seperti The American Society Dowsers, British Society of Dowser dan sebagainya. Di Indonesia meskipun belum dikenal secara luas dibeberapa daerah seperti Kota Purworejo ada seorang Dowser yang dikenal dengan Imam Romo Lukman, di Kota Pangkal Pinang dikenal Bruder Yanuar Husada, di Bogor ada Ibu Liliana Indrajaya yang menggunakan metode Dawsing untuk pengobatan yaitu mendeteksi energi yang berpengaruh negatif dalam rumah tinggal pasien.

Aliran medan geopatis ini dapat mempengaruhi kesehatan dan konsentrasi manusia terutama jika manusia dalam melakukan aktivitas atau beristirahat berada diatas medan energi tersebut dalam waktu lama (tidur dan kerja). Selain itu medan geopatis tersebut juga berpengaruh negatif terhadap peralatan elektronik (mempengaruhi kinerja atau memperpendek usia peralatan elektronik)

Jika aliran geopatis yang merugikan manusia dapat dipetakan didalam perancangan fungsi hunian khususnya dalam menentukan zoning dan blocking tentunya dapat membantu manusia menghindari efek negatif yang dihasilkan oleh aliran tersebut. Dalam mengidentifikasi dan memetakan pola medan geopatis pad adesain hunian dengan metode Dawsing, maka seorang 
dawser dengan menggunakan media/alat lacak yang cocok baginya melakukan beberapa langkah seperti bergerak keseluruh lahan/ruangan apabila terdapat medan geopatis maka alat yang digunakan akan tertarik ke bawah, kemudia dilakukan gerakan ulangan untuk memastikan titik pasti dan diberi tanda. Pemberian tanda tersebut dilakukan diseluruh lahan/ ruangan yang memiliki medan geopatis. Setelah selesai diidentifikasi dilakukan pengukuran untuk memetakan titik-titik tersebut pada gambar denag laha/ruangan dan dihubungkan sehingga tergambar pola medan geopatisnya. Dengan demikian didapatkanlah daerah mana saja yang dilewati oleh aliran medan geopatis. Oleh karena itu, pertanyaan dalam penelitian ini adalah "Bagaimanakah hasi pemetaan aliran medan geopatis pada lahan yang digunakan untuk membangun rumah tinggal yang harmonis dengan alam serta bagaimakah solusinya?"

\subsection{Penyebab Medan Geopatis}

Medan geopatis umumnya disebabkan oleh aliran bawah tanah yang bersifat bipolar yang mempunyai dua kutub yaitu positif dan negatif serta mengandung banyak mineral dalam bentuk ion yang bermuatan listrik. Pada saat mengalir, molekul-molekuk air tersebut berputar seperti pada dynamo kemudian mengalami gesekan dengan batu ataupun benda-benada lain di bawah tanah. Efek gesekan yang terus menerus tersebut menimbulkan listrik statis sebesar 20-5-v/m (Heinz Frick,1998, hal 138). Putaran dan gesekan air dalam tanah tersebut menghasilkan aliran elektromagnetik yang arahnya lurus ke atas permukaan tanah, inilah yang dapat menyebabkan ganguan kesehatan bagi manusia jika manusia berada diatas medan tersebut dalam waktu lama.

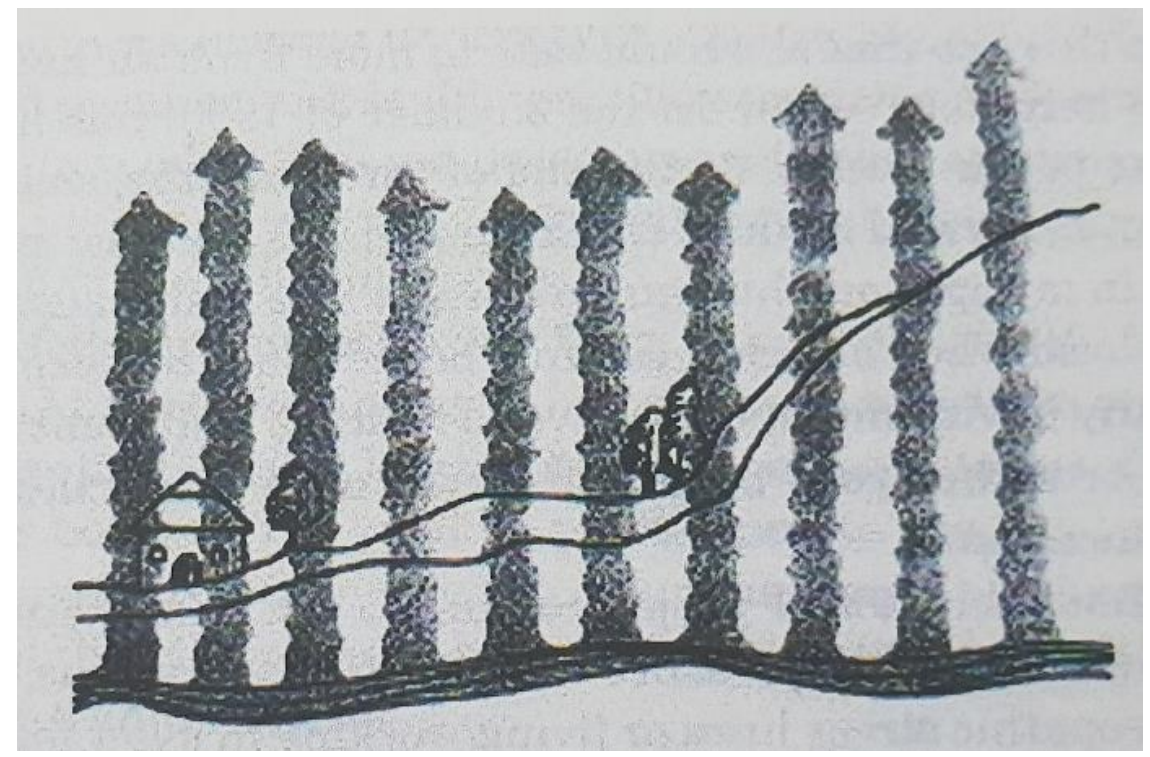

Gambar 1. Medan Geopatis Akibat Aliran Bawah Tanah

Sumber: T.Y.Lim, hal. 52

Selain medan geopatis, jaringan magnetis atau jaringan Hartman atau Curry yang merupakan suatu jaringan sistematis terbagi diatas bola bumi dan terdiri atas garis-garis lurus, jaringan gaya berkisi-kisi pada seluruh permukaan bumi adalah jaringan magnetis yang diselidiki oleh dokter-dokter yang mencari hubungan antara penyakit manusia dengan tempat tinggalnya. Jaringan Hartman berorientasi utara-selatan dengan garis yang memiliki pengarus selebar 15$25 \mathrm{~cm}$ dengan jarak 2-3 meter. Sedangkan jaringan Curry berorientasi miring terhadap jaringan Hartman dengan garis yang memiliki pengaruh sebesar $50 \mathrm{~cm}$ dengan jarak 3,5-7 
meter. Semua jaringan baik Hartman dan Curry memiliki medan elektromagnetis yang lebih tinggi daripada tanag sebelahnya ( Heinz Frick, hal 142)

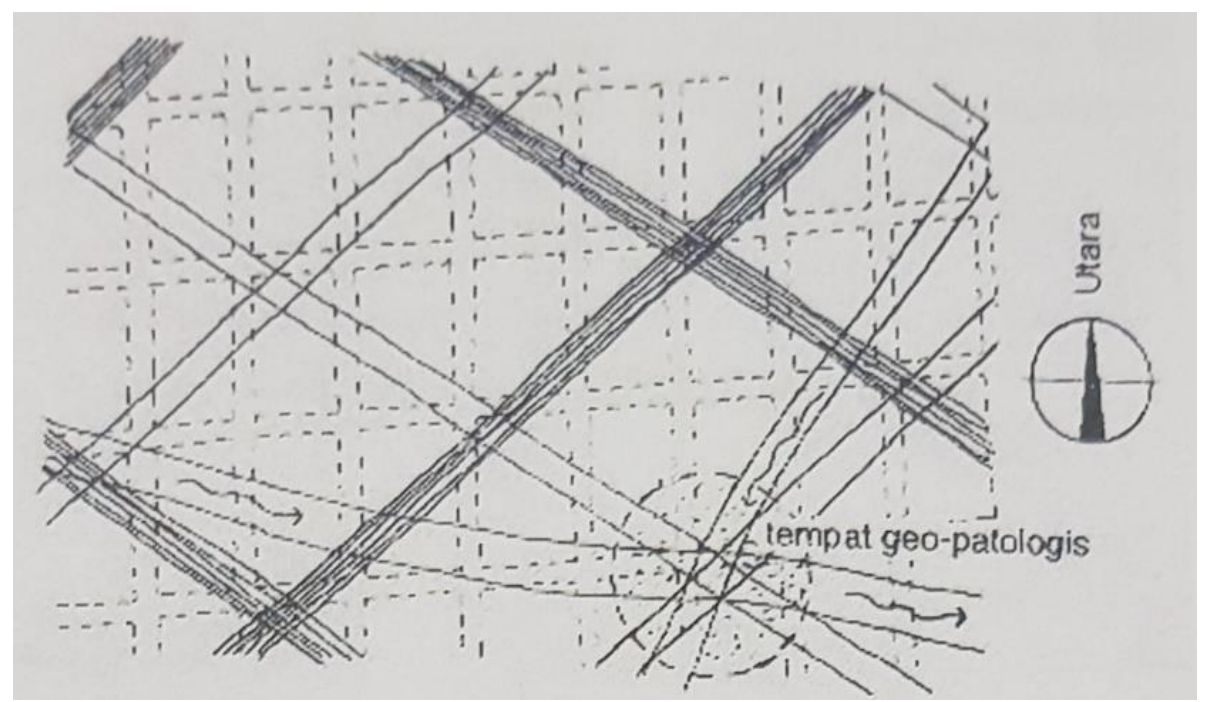

Gambar 2. Peta Jaringan Hartman dan Curry, serta Aliran Air Bawah Tanah Sumber: Heinz Frick, hal. 142

Dislokasi dalam kerak bumi kearah horizontal maupun vertikal mengakibatkan suatu perubahan radiasi teristis disebut patahan dan dislokasi geologis menurut Heinz juga dapat mengakibatkan kanker jika manusia terus menerus tidur diatas tempat tersebut. Hubungan adanya air yang mengalir pada patahan, retakan atau dislokasi geologis atau tidak dibedakan antara patahan atau dislokasi kering dan patahan atau dislokasi basah.

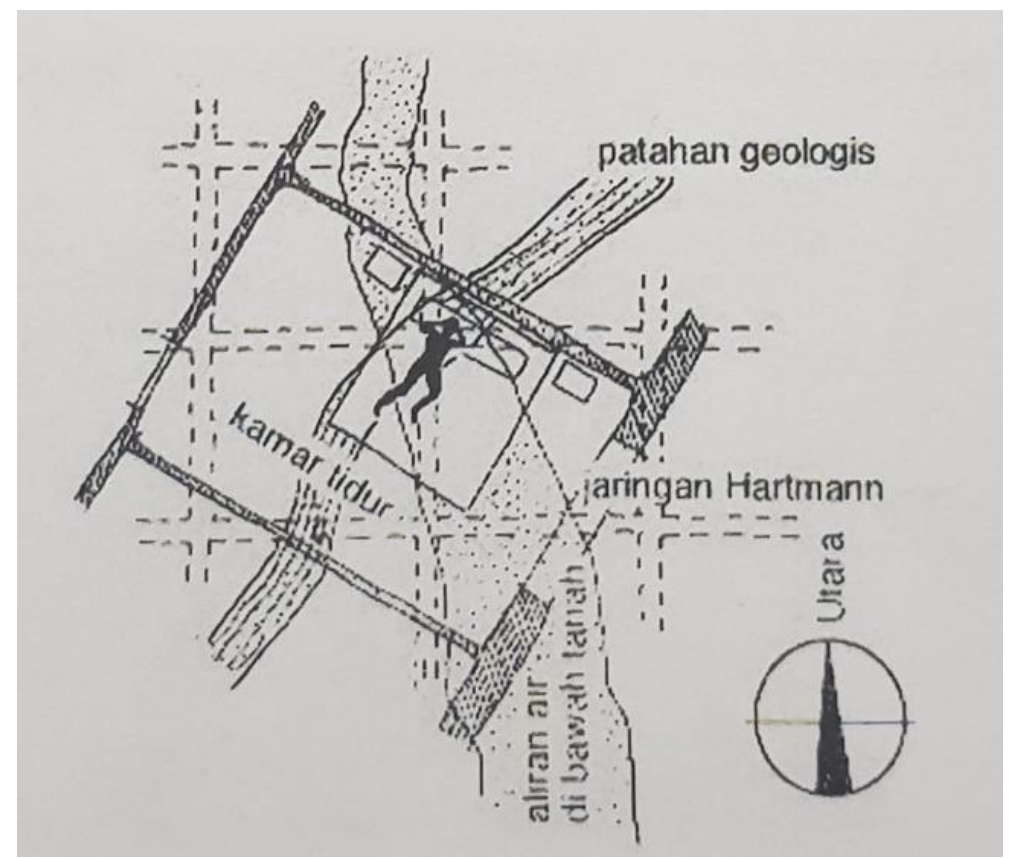

Gambar 3. Gambar Ruang Tidur, patahan geologis dan persilangan aliran air bawah tanah serta jaringan Hartman yang mempengaruhi kesehatan orang yang tidur di atasnya Sumber: Heinz Frick, hal 143 
Selain jaringan Hartman dan dislokasi geologis penyebab medan geopatis adalah Lay Lines. Lay Lines merupakan garis yang dibentuk dari energi kosmis/alam dan merupakan bagian dari system energi bumi yang masuk ke bumi pada suatu titik yang disebut power center hingga kedalaman kurang lebih 81 meter dibawah permukaan tanah dan kemudian berbelok 90 derajat dan keluar menuju permukaan tanah secara vertical pada titik yang lain. Lebar garis ini kurang lebih $167 \mathrm{~cm}$ dan panjang bervariasi hingga ribuan mill. Pada titik keluar garis ini meninggalkan permukaan tanah hampir $70 \%$ merupakan air mancur/ astesis. Beberapa bangunan monumental dan tempat-tempat suci kuno berdiri segaris dengan garis ini. System Lay Lines ditemukan oleh Albert Watkins. (pettis, Chuck and The Geo Group, FINDING PLACE OF POWER: Dowsing earth energies, 2000)

\subsection{Pengaruh Medan Geopatis Terhadap Manusia}

Penelitian tentang pengaruh medan geopatis terhadap fungsi tubuh manusia telah dilaksakan secara ilmiah oleh Dr. Bergsmann seorang konsultan dalam bidang kesehatan dan obat dari sebuah universitas di Vienna pada tahun 1990. Penelitain tersebut menguji 24 parameter dari 985 orang sampel dan menggunakan 3 orang jasa dawser untuk menentukan lokasi yang memiliki medan geopatis dan lokasi yang netral pada 8 ruangan dalam beberapa Rumah Sakit di Austria. Hasilnya tercatat ada 500.000 data yang diolah secara kuantitatif dievaluasi dan dianalisa yang menunjukan bahwa terdapat perubahan tubuh secara signifikan akibat pengaruh medan geopatis.

Berbeda dengan manusia, pengaruh radiasi ini justru disukai oleh beberapa bianatang seperti kucing, burung, lebah, ular, rayap dan semut yang selalu membuat sarangnya diatas pengaruh radiasi medan geopatis. Sedangkan beberapa binatang lain seperti anjing, sapi, domba,kuda tidak menyukai medan geopatis.

Benda-benda berupa barang eletromagneik seperti TV, komputer, audio video, dll akan mengalami ermudungser scheinungen atau disebut pelapukan logam sehingga akan cepat rusak bila berada diatas pancaran radiasi medan geopatis. (Yosef Glinka, Intisari hal 157-158)

\section{METODE PENELITIAN}

Penelitian ini menggunakan data primer, yaitu data yang dikumpukan dan diolah sendiri oleh peneliti secara langsung dari objeknya (Wawan 2001: 5-6) karena penelitian ini merupakan penelitian yang perlu melihat dan mengukur langsung dari lokasi yang ada. Objek penelitian dikunjungi, diukur dan dipastikan posisi dan aliran medan geopatis dari araea yang akan diteliti menggunakan alat pengukur medan geopatis. Selain menggunakan data primer penelitian ini juga menggunakan data sekunder berupa informasi dari beberapa sumber pustaka. Data visual dari hasil pemetaan dan pengukuran dibutuhkan untuk analisa lebih lanjut sehingga perancang dapat menata zoning dan blocking untuk objek studi.

\section{HASIL PENELITIAN}

Lahan hunian yang digunakan sebagai objek penelitian adalah lahan di Jalan Budi Indah no.9 dengan luas tanah sekitar 1280 meter persegi dengan panjang dan lebar lahan yaitu 32 meter 
x 40 meter dengan bentuk persegi panajng. Perencanaan rumah tinggal tersebut terdiri dari 1 kamar tidur utama, 4 kamar tidur, ruang keluarga, dapur kotor dan dapur ersih, ruangan maka, ruang kerja, ruang baca, ruang fitness, kamar mandi dan area servis. Hunian ini akan ditinggali oleh sepasang lansia, suami, istri dan anak-anaknya. Hasil dari pencarian medan geopatis di lapangan menunjukkan terdapat 5 titik medan geopatis sebagai berikut.

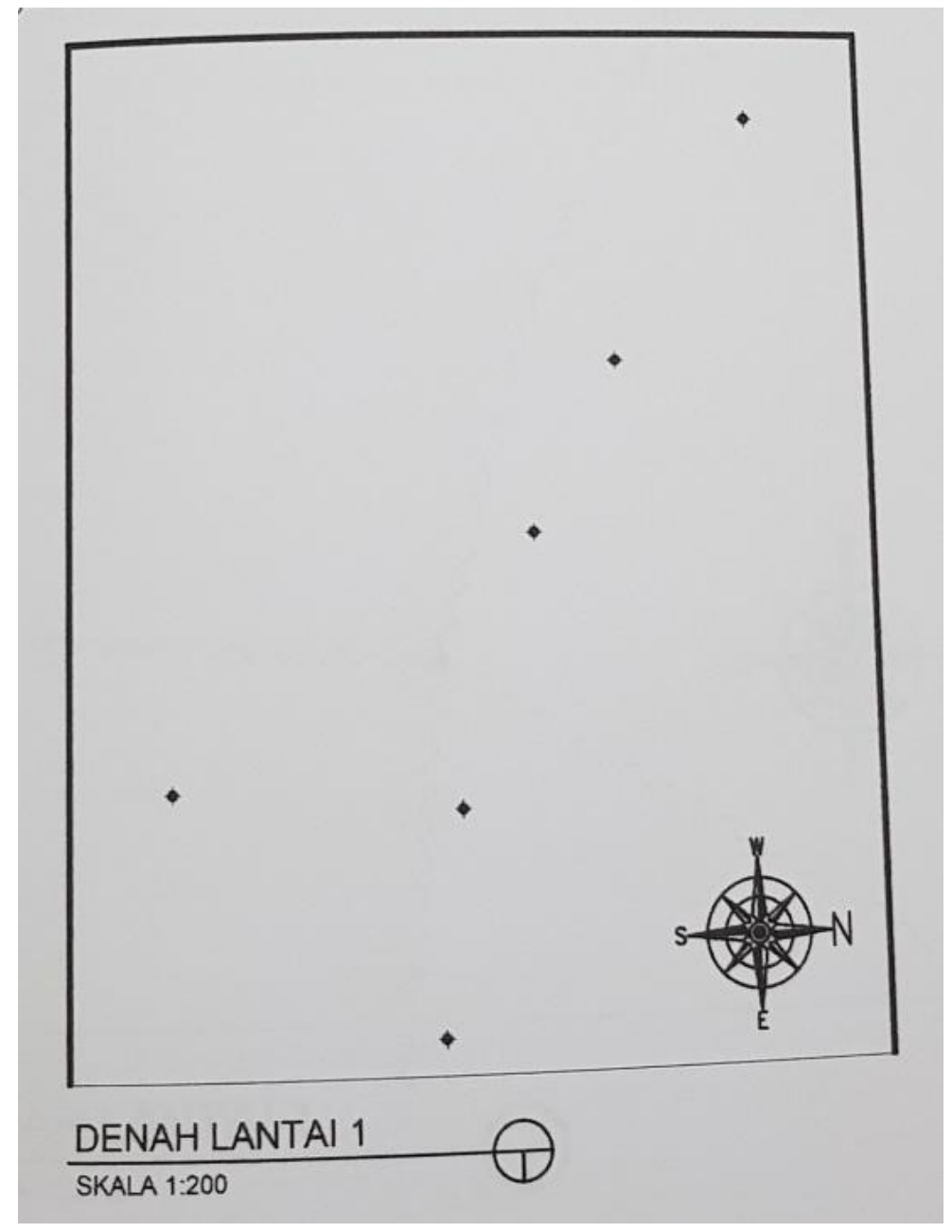

Gambar 4. Titik Medan Geopatis Yang Ditemukan Di Lokasi

Dari hasil identifikasi awal tersebut ke-5 titik tersebut diukur dan digambarkan pola aliran medan geopatisnya. Hasilnya didapatkan ada 2 pola aliran medan geopatis yang perlu dihindari dari lahan yang akan dijadikan rumah tinggal. Pola aliran pertama bergerak dari arah timur ke barat laut atau daria rah muka lahan kea rah kanan belakang lahan sehingga seakan-akan membagi lahan menjadi dua bagian. Pola aliran ke-2 bergerak dari arah timur laut kea rah tenggara. Pola aliran medan geopatis dapat dilihat dari gambar pemetaannya sebagai berikut. 


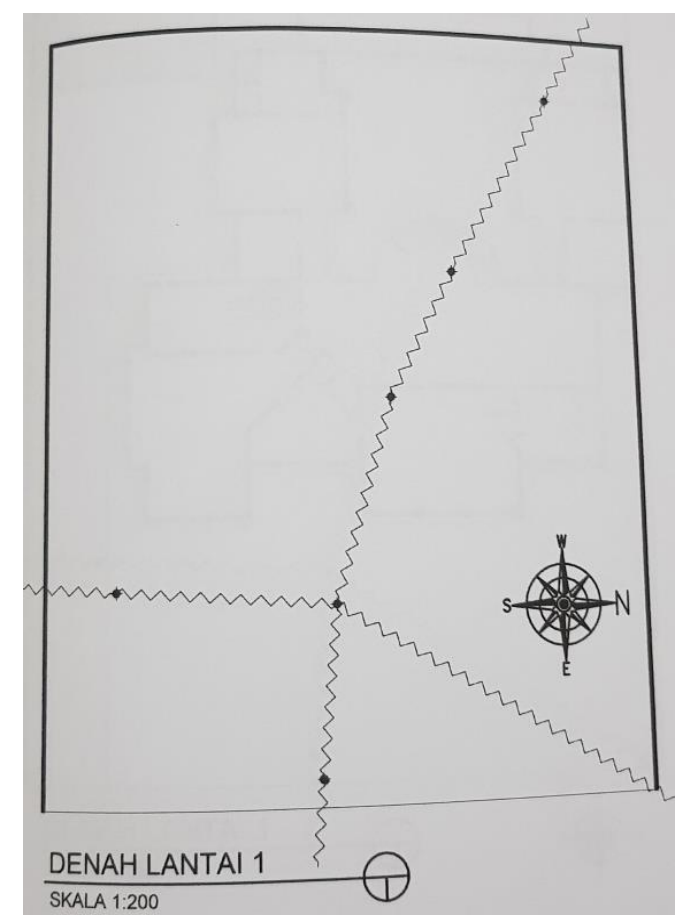

Gambar 5. Titik Medan Geopatis Yang Digambarkan Pola Alirannya

Selanjutnya pola aliran medan geopatis yang telah terukur dan tergambar menjadi panduan perencanaan dalam membuat zoning dan blocking perancangan hunian. Bagian lahan yang terlewati oleh aliran medan geopatis sebaiknya dihindari untuk fungsi private khususnya ruang tidur. Hal ini dilakukan agar manusia yang akan beristirahat di dalam ruang tidur dapat terhindar dari efek negatif dari medan geopatis. Berikut penjelasannya.

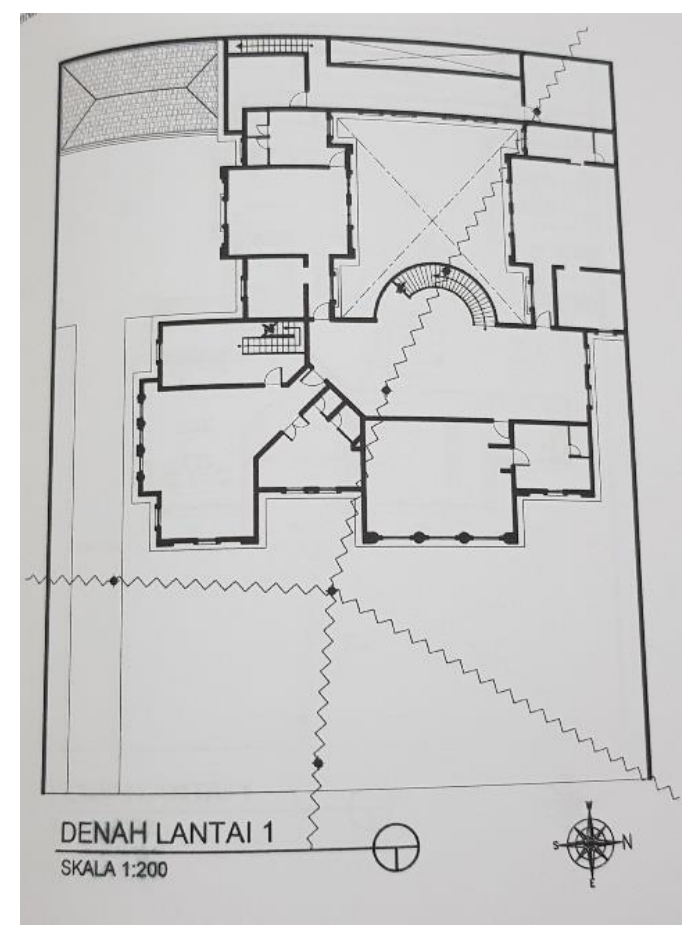

Gambar 6. Zoning dan Blocking Perencanaan Rumah 
Dari gambar terakhir dapat dilihat, solusi yang di dapat dari penempatan zoning dan blocking untuk area privat atau ruangan yang dipakai dalam waktu yang cukup lama pada rumah tinggal di jalan budi indah no 9, Bandung ini tidak tepat diatas titik maupun aliran medan geopatis. Penelitian dan analisa awal seperti ini sangat penting dalam tahap awal perancangan penentuan Zoning dan Blocking, karena seperti yang dipaparkan pada penelitian yang pernah dilakukan bahwa jika manusia beraktifitas terlalu lama atau berada cukup lama diatas titik dan aliran medan geopatis akan berdampak tidak baik terutama pada kesehatannya.

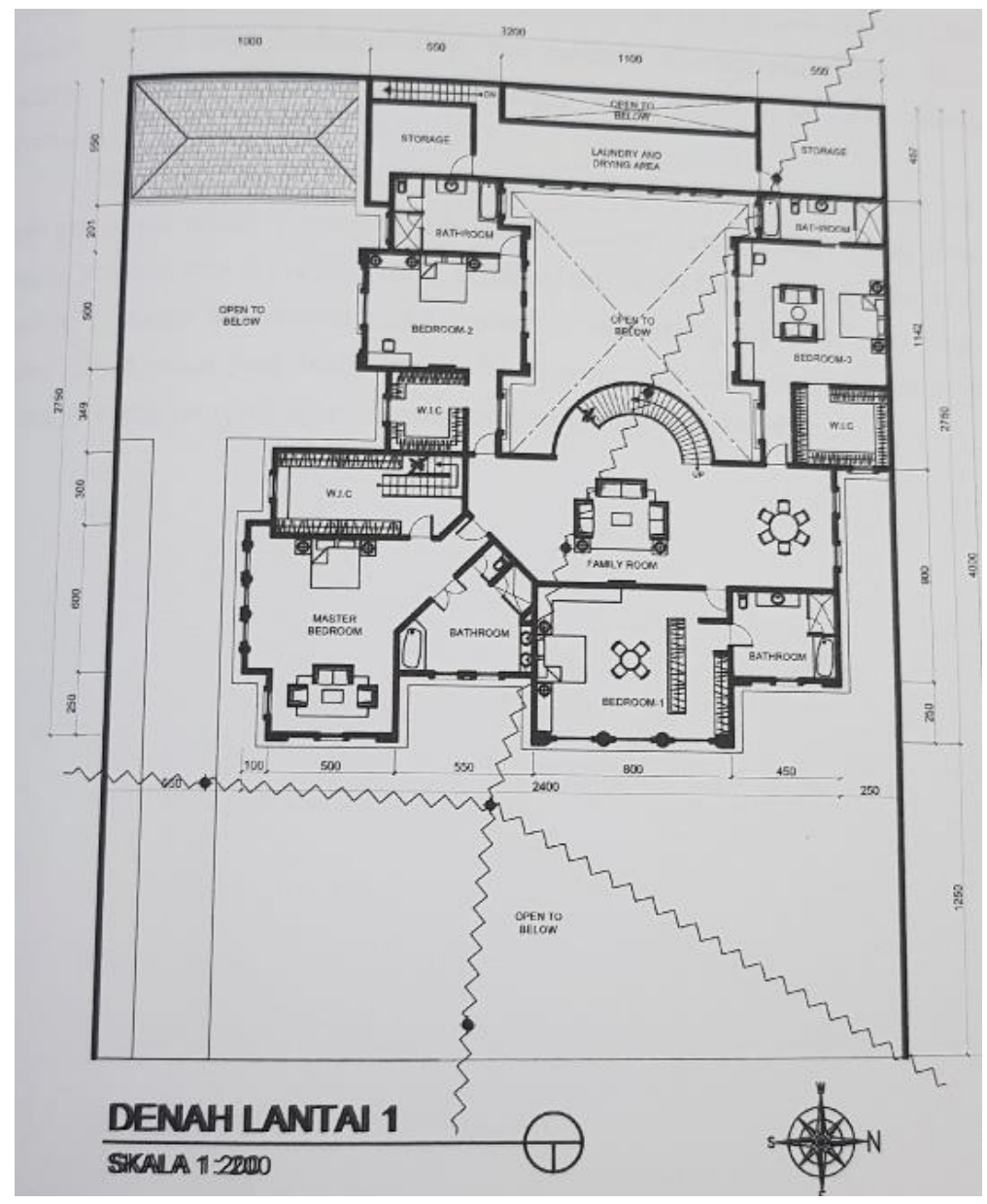

Gambar 7. Perencanaan Denah Rumah

Dalam penempatan ruangan yang didapat dari penelitian ini, area dalam rumah yang terlewati aliran medan geopatis adalah tembok pemisah kamar dengan kamar mandi, bagian samping area duduk dari ruang keluarga, area tanah kosong di tengah taman dan gudang. Sehingga seluruh area kamar terutama ranjang dan di area lain yang dipakai dalam waktu cukup lama tidak terlewat garis aliran geopatis dan bersih sehingga energi yang ada di area tersebut tidak mengganggu penghuninya.

\section{KESIMPULAN}

Medan geopatis merupakan aliran tak kasat mata yang disebabkan oleh aliran bawah tanah, tumpukan mineral, kisi bumi dan sebagainya. Energi negative yang dihasilkan perlu dihindari agar manusia dapat terbebas dari dampak negative medan geopatis. Hasil pengidentifikasian 
aliran medan geopatis dapat membantu seorang perencana dalam merencanakan dan merancang desain hunian yang selaras dengan alam sehingga manusia yang tinggal didalamnya dapat memperoleh keuntungan berupa kondisi yang sehat sesuai fungsi dari sebuah rumah tinggal yaitu tempat berlindung, beristirahat dan membangun sebuah keluarga.

\section{DAFTAR PUSTAKA}

Applegate George, 1997, The Complete Book of Dowsing, The Definitive Guide To Finding Underground Water, Element Books Limited, Shaftesburry-Dorset-RockportMassachussetts-Melbourne-Victoria.

Heinz Frick dan FX Bambang Suskiyatno, 1998, Dasar Dasar Eko Arsitektur, Soegijapranata University Press, Kanisius.

Procter, Roy and And,2000, Healing Sick Houses, Gill\&Macmillian Ltd, Dublin.

Nielsen, Greg \& Joseph Polansky, 1996, Rahasia Daya Pendulum, Dahara Prize, Semarang.

Glinka, Prof. Yosef, 1996, Hindarkan Rumah dari Ancaman Geopati, majalah Intisari, Mei 1996, Hal 156-157. 